\title{
Light Absorption in Some Substituted Methiodides of Stilbazoles
}

\author{
S. P. TANDON and M. P. BHutra \\ Physical Laboratories, University of Jodhpur, Jodhpur, India \\ (Z. Naturforsch. 25 b, 343-346 [1970] ; eingegangen am 15. November 1969)
}

\begin{abstract}
The absorption spectra of $2^{\prime}$ hydroxy 1-methyl 2-stilbazolium iodide, 3 ' hydroxy 1-methyl 2-stilbazolium iodide, $3^{\prime}: 4^{\prime}$ dihydroxy 1-methyl 2 -stilbazolium iodide and $4^{\prime}$ hydroxy $3^{\prime}$ methoxy l-methyl 2 -stilbazolium iodide in different solvents have been studied in the region $200 \mathrm{~m} \mu-1100 \mathrm{~m} \mu$. Three bands have been observed in their solutions in different solvents. Based on the available evidences the bands have been assigned to different intramolecular transitions.
\end{abstract}

The benzene molecule has $\mathrm{D}_{6 \mathrm{~h}}$ symmetry ${ }^{1}$. Its ground state is ${ }^{1} \mathrm{Ag}_{1 \mathrm{~g}}$ and the excited singlet states are ${ }^{1} \mathrm{~B}_{2 \mathrm{u}} ;{ }^{1} \mathrm{~B}_{1 \mathrm{u}}$ and ${ }^{1} \mathrm{E}_{1 \mathrm{u}}$ and the lowest triplet state is ${ }^{3} \mathrm{~B}_{1 \mathrm{u}}$. The energy of the transitions increase ${ }^{1,2}$ in the order ${ }^{3} \mathrm{~B}_{1 \mathrm{u}} \leftarrow{ }^{1} \mathrm{~A}_{1 \mathrm{~g}}<{ }^{1} \mathrm{~B}_{2 \mathrm{u}} \leftarrow{ }^{1} \mathrm{~A}_{1 \mathrm{~g}}<{ }^{1} \mathrm{~B}_{1 \mathrm{u}} \leftarrow{ }^{1} \mathrm{~A}_{1 \mathrm{~g}}<$ ${ }^{1} \mathrm{E}_{1 \mathrm{u}} \leftarrow{ }^{1} \mathrm{~A}_{1 \mathrm{~g}}$. The first three transitions are forbidden ones and give rise ${ }^{2}$ to origins of the bands at 340,264 and $206.8 \mathrm{~m} \mu$ respectively. The transition ${ }^{1} \mathrm{E}_{1 \mathrm{u}} \leftarrow{ }^{1} \mathrm{~A}_{1 \mathrm{~g}}$ is an allowed one and gives rise to the intense band near $185 \mathrm{~m} \mu$. The substitution of aza-group $(-\mathrm{N}=)$ for the methine group $(=\mathrm{CH}-)$ in benzene does not change the energies of the $\pi$ - and $\pi^{*}$ orbitals appreciably but disturbs the molecular symmetry changing it from $\mathrm{D}_{6 \mathrm{~h}}$ to $\mathrm{C}_{\varrho_{v}}$. Consequently, though there is little change in the energies of the transitions, the intensities of the bands of pyridine ${ }^{3}$ are much higher than those of the corresponding bands of benzene. In addition to the transitions of benzene, in pyridine ${ }^{1}$ the forbidden $\mathrm{n} \rightarrow \pi^{*}$ transitions due to the excitation of the electron from the lone-pair of orbitals localized predominantly on nitrogen to $\pi^{*}$-orbitals are expected to have energies smaller than ${ }^{1} \mathrm{~B}_{1 \mathrm{u}} \leftarrow{ }^{1} \mathrm{~A}_{1 \mathrm{~g}}$ transition of benzene. The presence ${ }^{4}$ of weak bands $(f \sim 0.003)$ due to $\mathrm{n} \rightarrow \pi^{*}$ transitions buried under strong $\pi \rightarrow \pi^{*}$ transitions have also been detected in the case of pyridine and picolines. The bands due to $\mathrm{n} \rightarrow \pi^{*}$ transitions in carbonyl groups have also been observed near $300 \mathrm{~m} \mu$. The spectra of methiodides of stilbazoles are expected to be similar to that of pyridine. However, their spectra have not been studied systematically.

1 H. H. JAFFE' and M. ORChIN, Theory and Application of Ultraviolet Spectroscopy, John Wiley and Sons, Inc., New York 1962.

2 H. Suzuki, Electronic Absorption Spectra and Geometry of Organic Molecules, Academic Press, New York 1967.
Consequently it was thought worthwhile to study their spectra in different solvents.

The present communication reports the absorption spectra of $2^{\prime}$ hydroxy 1-methyl 2-stilbazolium iodide, 3 ' hydroxy 1-methyl 2 -stilbazolium iodide, $3^{\prime}: 4^{\prime}$ dihydroxy 1-methyl 2 -stilbazolium iodide and $4^{\prime}$ hydroxy $3^{\prime}$ methoxy 1-methyl 2-stilbazolium iodide, which will hereafter be referred to as derivatives 1, 2, 3 and 4 respectively, in different solvents. The results have been interpreted in the light of the theoretical studies of the parent molecules.

The structure of these derivatives is that of the unhindered stilbene derivatives ${ }^{1,2}$ with the difference that in one ring the quaternary nitrogen is present which is strongly bonded to $-\mathrm{CH}_{3}$ group and loosely to the iodide ion, and in the other ring the $-\mathrm{OH}$ or $-\mathrm{OCH}_{3}$ groups or both are substituted in different positions.

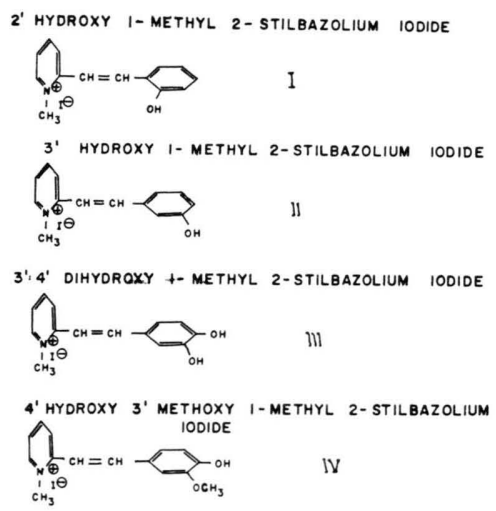

3 R. A. Fridel and M. Orchin, Ultraviolet Spectra of Aromatic Compounds, John Wiley and Sons, Inc., New York 1951.

4 H. P. Stephanson, J. chem. Physics 22, 1077 [1954]. 


\section{Results and Discussion}

\section{Spectrum}

Three bands have been observed. They have been classified as bands $\mathrm{A}, \mathrm{B}$ and $\mathrm{C}$ starting from the longest wavelength. The characteristics of the bands in different solvents have been collected in Tables $1-4$.
Band $A$

It is located at $550-560 \mathrm{~m} \mu$ in DMF and shifts to $430 \mathrm{~m} \mu$ in the case of alkaline aqueous solution of derivative 1. The band does not appear in derivative 2 in any other solvent. It is quite intense as is obvious from the values of molar extinction coefficient $\left(\varepsilon_{\max }\right)$, oscillator strength $(f)$, dipole strength $\left(D_{\mathrm{nm}}\right)$ and Einstein's Coefficients $\left(A_{\mathrm{mn}}\right.$ and

\begin{tabular}{|c|c|c|c|c|c|c|c|c|c|}
\hline \multirow[t]{2}{*}{ Solvent } & \multirow[t]{2}{*}{ Band } & \multicolumn{2}{|c|}{ Band Position } & \multicolumn{6}{|c|}{ Intensity } \\
\hline & & {$[\mathrm{m} \mu]$} & {$\left[\mathrm{cm}^{-1}\right]$} & $\begin{array}{c}\varepsilon_{\max } \\
\text { [litres/ } \\
\text { mole-cm] }\end{array}$ & $f$ & $\begin{array}{c}D_{\mathrm{nm}} \\
{\left[\AA^{2}\right]}\end{array}$ & $\begin{array}{c}A_{\mathrm{mn}} \\
{\left[\times 10^{9}\right]} \\
{\left[\mathrm{sec}^{-1}\right]}\end{array}$ & $\begin{array}{c}B_{\mathrm{nm}} \\
{\left[\times 10^{9}\right]} \\
{\left[\mathrm{sec}^{-1}\right]}\end{array}$ & $\begin{array}{l}\text { Lifetime } \\
T[\text { sec. }] \\
{\left[\times 10^{-9}\right]}\end{array}$ \\
\hline \multirow[t]{2}{*}{ DMF } & A & 550 & 18182 & 3820 & 0.05 & 0.3 & 0.01 & 0.4 & 89.3 \\
\hline & B & 370 & 27027 & 19317 & 0.5 & 1.8 & 0.2 & 2.5 & 4.0 \\
\hline \multirow[t]{2}{*}{ Methanol } & B & 370 & 27027 & 15060 & 0.3 & 1.04 & 0.1 & 1.5 & 6.7 \\
\hline & $\mathrm{C}$ & 230 & 43478 & 4950 & 0.1 & 0.2 & 0.1 & 0.3 & 9.2 \\
\hline \multirow[t]{3}{*}{ Water } & B & 360 & 27777 & 16358 & 0.5 & 1.7 & 0.3 & 2.5 & 3.8 \\
\hline & $\mathrm{C}$ & 221 & 45249 & 3659 & 0.05 & 0.1 & 0.1 & 0.1 & 15.6 \\
\hline & A & 430 & 23256 & 13990 & 0.3 & 1.2 & 0.1 & 1.7 & 9.4 \\
\hline \multirow{2}{*}{$\begin{array}{l}\text { Alkaline } \\
\text { water }\end{array}$} & B & 330 & 30303 & 11031 & 0.3 & 0.8 & 0.2 & 1.2 & 6.2 \\
\hline & C & 220 & 45454 & 3551 & 0.06 & 0.1 & 0.1 & 0.2 & 12.4 \\
\hline
\end{tabular}

Table 1. Characteristics of bands A, B and C of $2^{\prime}$ hydroxy l-methyl 2-stilbazolium iodide in different solvents.

\begin{tabular}{|c|c|c|c|c|c|c|c|c|c|}
\hline \multirow[t]{2}{*}{ Solvent } & \multirow[t]{2}{*}{ Band } & \multicolumn{2}{|c|}{ Band Position } & \multicolumn{6}{|c|}{ Intensity } \\
\hline & & {$[\mathrm{m} \mu]$} & {$\left[\mathrm{cm}^{-1}\right]$} & $\begin{array}{c}\varepsilon_{\max } \\
\text { [litres/ } \\
\text { mole-cm.] }\end{array}$ & $f$ & $\begin{array}{l}D_{\mathrm{nm}} \\
{\left[\AA^{2}\right]}\end{array}$ & $\begin{array}{c}A_{\mathrm{mn}} \\
{\left[\times 10^{9}\right]} \\
{\left[\mathrm{sec}^{-1}\right]}\end{array}$ & $\begin{array}{c}B_{\mathrm{nm}} \\
{\left[\times 10^{9}\right]} \\
{\left[\sec ^{-1}\right]}\end{array}$ & $\begin{array}{c}\text { Lifetime } \\
T .\left[\mathrm{sec}^{-1}\right] \\
{\left[\times 10^{-9}\right]}\end{array}$ \\
\hline DMF & B & 342 & 29240 & 23138 & 0.6 & 1.9 & 0.3 & 2.8 & 2.8 \\
\hline \multirow[t]{2}{*}{ Methanol } & B & 340 & 29412 & 21308 & 0.6 & 1.8 & 0.3 & 2.6 & 3.0 \\
\hline & C & 218 & 45871 & 3228 & 0.04 & 0.1 & 0.1 & 0.1 & 18.5 \\
\hline \multirow[t]{2}{*}{ Water } & B & 334 & 29940 & 20286 & 0.4 & 1.4 & 0.3 & 2.0 & 3.7 \\
\hline & $\mathrm{C}$ & 225 & 44444 & 5381 & 0.1 & 0.2 & 0.1 & 0.3 & 8.1 \\
\hline \multirow{2}{*}{$\begin{array}{l}\text { Alkaline } \\
\text { water }\end{array}$} & B & 340 & 29412 & 21201 & 0.5 & 1.6 & 0.3 & 2.3 & 3.4 \\
\hline & $\mathrm{C}$ & 227 & 44053 & 4950 & 0.1 & 0.2 & 0.1 & 0.3 & 2.1 \\
\hline
\end{tabular}

Table 2. Characteristics of bands B and C of 3' hydroxy l-me thyl 2-stilbazolium iodide in different solvents.

\begin{tabular}{|c|c|c|c|c|c|c|c|c|c|}
\hline \multirow[t]{2}{*}{ Solvent } & \multirow[t]{2}{*}{ Band } & \multicolumn{2}{|c|}{ Band Position } & \multicolumn{6}{|c|}{ Intensity } \\
\hline & & {$[\mathrm{m} \mu]$} & {$\left[\mathrm{cm}^{-1}\right]$} & $\begin{array}{c}\varepsilon_{\max } \\
\text { [litres/ } \\
\text { mole-cm.] }\end{array}$ & $f$ & $\begin{array}{c}D_{\mathrm{nm}} \\
{\left[\AA^{2}\right]}\end{array}$ & $\begin{array}{c}A_{\mathrm{mn}} \\
{\left[\times 10^{9}\right]} \\
{\left[\mathrm{sec}^{-1}\right]}\end{array}$ & $\begin{array}{c}B_{\mathrm{nm}} \\
{\left[\times 10^{9}\right]} \\
{\left[\mathrm{sec}^{-1}\right]}\end{array}$ & $\begin{array}{c}\text { Lifetime } \\
\cdot\left[\times 10^{-9}\right] \\
{[\mathrm{sec}]}\end{array}$ \\
\hline \multirow[t]{3}{*}{ DMF } & A & 560 & 17857 & 22348 & 0.3 & 1.7 & 0.1 & 2.5 & 14.3 \\
\hline & B & 400 & 25000 & 10906 & 0.3 & 1.0 & 0.1 & 1.4 & 9.2 \\
\hline & $\mathrm{C}$ & 282 & 35460 & 962 & 0.01 & 0.03 & 0.01 & 0.05 & 98.0 \\
\hline \multirow[t]{2}{*}{ Methanol } & B & 400 & 25000 & 21920 & 0.5 & 1.8 & 0.2 & 2.7 & 4.8 \\
\hline & C & 280 & 35714 & 1603 & 0.01 & 0.03 & 0.01 & 0.05 & 89.3 \\
\hline \multirow[t]{2}{*}{ Water } & B & 372 & 26882 & 19354 & 0.5 & 1.6 & 0.2 & 2.4 & 4.3 \\
\hline & C & 270 & 37030 & 1176 & 0.01 & 0.03 & 0.01 & 0.04 & 92.6 \\
\hline Alkaline & B & 440 & 22727 & 6522 & 0.2 & 0.7 & 0.1 & 1.0 & 17.3 \\
\hline water & C & 270 & 27027 & 1817 & 0.03 & 0.1 & 0.02 & 0.1 & 41.0 \\
\hline
\end{tabular}

Table 3. Characteristics of bands A, B and C of $3^{\prime}: 4^{\prime}$ dihydroxy 1-methyl 2-stilbazolium iodide in different solvents. 


\begin{tabular}{|c|c|c|c|c|c|c|c|c|c|}
\hline \multirow[t]{2}{*}{ Solvent } & \multirow[t]{2}{*}{ Band } & \multicolumn{2}{|c|}{ Band Position } & \multicolumn{6}{|c|}{ Intensity } \\
\hline & & {$[\mathrm{m} \mu]$} & {$\left[\mathrm{cm}^{-1}\right]$} & $\begin{array}{c}\varepsilon_{\max } \\
{[\text { litres/ }} \\
\text { mole-cm.] }\end{array}$ & $f$ & $\begin{array}{l}D_{\mathrm{nm}} \\
{\left[\AA^{2}\right]}\end{array}$ & $\begin{array}{c}A_{\mathrm{mn}} \\
{\left[\times 10^{9}\right]} \\
{\left[\mathrm{sec}^{-1}\right]}\end{array}$ & $\begin{array}{c}B_{\mathrm{nm}} \\
{\left[\times 10^{9}\right]} \\
{\left[\mathrm{sec}^{-1}\right]}\end{array}$ & $\begin{array}{c}\text { Lifetime } \\
\cdot\left[\times 10^{-9}\right] \\
{[\mathrm{sec}]}\end{array}$ \\
\hline \multirow[t]{3}{*}{ DMF } & A & 560 & 17857 & 8800 & 0.1 & 0.5 & 0.2 & 0.7 & 4.8 \\
\hline & $\mathrm{B}$ & 390 & 25641 & 17400 & 0.4 & 1.5 & 0.2 & 2.2 & 5.5 \\
\hline & $\mathrm{C}$ & 275 & 36363 & 900 & 0.01 & 0.02 & 0.01 & 0.03 & 138.9 \\
\hline \multirow[t]{2}{*}{ Methanol } & B & 390 & 25641 & 17300 & 0.4 & 1.6 & 0.2 & 2.3 & 5.3 \\
\hline & $\mathrm{C}$ & 268 & 37317 & 1300 & 0.02 & 0.05 & 0.02 & 0.1 & 56.5 \\
\hline \multirow[t]{2}{*}{ Water } & $\mathrm{B}$ & 374 & 26737 & 19000 & 0.5 & 1.6 & 0.2 & 2.3 & 4.6 \\
\hline & $\mathrm{C}$ & 270 & 37037 & 800 & 0.01 & 0.02 & 0.01 & 0.03 & 151.5 \\
\hline \multirow{2}{*}{$\begin{array}{l}\text { Alkaline } \\
\text { water }\end{array}$} & B & 450 & 22222 & 17900 & 0.5 & 1.9 & 0.2 & 2.8 & 6.6 \\
\hline & $\mathrm{C}$ & 276 & 36232 & 2600 & 0.04 & 0.1 & 0.04 & 0.2 & 26.6 \\
\hline
\end{tabular}

Table 4. Characteristics of bands A, B and C of $4^{\prime}$ hydroxy $3^{\prime}$ methoxy 1-methyl 2-stilbazolium iodide in different solvents.

$\left.B_{\mathrm{nm}}\right)$. Its intensity increases by changing the solvent from DMF to alkaline water.

The lifetime of the excited state varies between $10^{-8}$ and $10^{-9} \mathrm{sec}$ in the case of different solvents.

\section{Band $B$}

In DMF solvent the band B of derivative 2 is located at $342 \mathrm{~m} \mu$. It shifts to longer wavelengths in the order of derivatives 1,4 and 3 , i. e., 370, 390 and $400 \mathrm{~m} \mu$ respectively. The band exhibits a typical blue shift, when the solvents are changed in order of DMF-methanol-water. In alkaline water the band is situated at longer wavelengths than in water. The observed high intensity $\varepsilon_{\max } \sim 10^{4}, f$ $\sim 0.5 ; D_{\mathrm{nm}} \sim 1-1.9 \AA^{2}, A_{\mathrm{mn}} \sim(0.1-0.3) \times 10^{9}$ and $B_{\mathrm{nm}} \sim(1.0-2.7) 10^{9}$ suggests that the band is due to an allowed transition. The effect of solvent on intensity varies slightly for different derivatives. In the case of derivative 2 the loss of intensity parallels the blue shift when the solvents are changed in the order DMF-methanol-water. The estimated lifetime of the excited state of different derivatives in different solvents varies from $10^{-8}$ to $10^{-9}$ seconds.

\section{Band $C$}

The band is located at $225 \mathrm{~m} \mu$ in derivative 2 in water. The effect of solvent on the energy of the band is very small. The observed moderately high

5 H. H. JAFFE' and M. ORchin, J. chem. Soc. [London] 1960, 1078.

${ }^{6}$ H. Suzuki, Bull. chem. Soc. Japan 25, 145 [1952].

7 C. M. Anderson, L. G. Cole, and E. C. Gilbert, J. Amer. chem. Soc. 72, 1263 [1950].

8 D. Y. Curtin, H. Gruen, and B. A. Shoulders, Chem. and Ind. 1958, 1205.

9 D. F. DeTar and L. Carpino, J. Amer. chem. Soc. 78, 475 [1956]. intensity of the band $\varepsilon_{\max } \sim 800$ to 5300 litres/ mole-cm.; $f \sim 0.0007 ; D_{n \mathrm{~m}} \sim 0.01-0.2 \AA^{2}, A_{\mathrm{mn}}$ $\sim(0.006-0.1) \times 10^{9}$ and $B_{\mathrm{nm}} \sim(0.03-0.28)$ $\times 10^{9}$ suggests that the band is due to an allowed transition. The lifetime of the excited state of derivatives under study in different solvents varies between $10^{-8}$ and $10^{-9}$ seconds.

\section{Interpretation of spectra}

The spectra of the derivatives may be interpreted by considering the derivatives $\mathbf{1}-\mathbf{4}$ as unhindered derivatives of trans-stilbene. The trans-stilbene ${ }^{2,5,6}$ belongs to point group $\mathrm{C}_{2 \mathrm{~h}}$. Any MO-treatment neglecting interaction between non-neighbouring atoms is equivalent to considering the linear structure ${ }^{2,5,6}$. The $\pi \rightarrow \pi^{*},{ }^{1} \mathrm{~B} \leftarrow{ }^{1} \mathrm{~A}$ and ${ }^{1} \mathrm{H} \leftarrow{ }^{1} \mathrm{~A}$ transitions in trans-stilbenes have been studied ${ }^{1,5,7-13}$ and are known to give rise to bands near 311 and $228 \mathrm{~m} \mu$ respectively.

The substitution of $(-\mathrm{N}=)$ for $(=\mathrm{CH}-)$ group does not affect appreciably the values of $\pi$ and $\pi^{*}$ orbitals, but the bonding of $\mathrm{CH}_{3}$ to $\mathrm{N}$ and the substitution of a $-\mathrm{OH}$ or $\mathrm{OCH}_{3}$ group for $\mathrm{H}$ of the other phenolic ring are expected to change the energies of the orbitals. The substitution of $\mathrm{OH}$ in the phenolic ring causes a red shift of the bands. So the shift of band B of derivative 1 to wavelengths longer than that of corresponding band $(\sim 311 \mathrm{~m} \mu)$

10 M. Katayama, S. Fujiward, H. Suzuki, Y. Nagai, and O. Simamura, J. molecular Spectroscopy. 5, 85 [1960].

11 J. P. Saxena, W. H. Stafford, and W. L. Stafford, J. chem. Soc. [London] 1959, 1579.

12 R. N. Beale and E. M. F. Roe, J. Amer. chem. Soc. 74, 2302 [1962].

13 O. Simamura and H. Suzuki, Bull. chem. Soc. Japan 27, 231 [1954]. 
of trans-stilbene, may be attributed to the substitution of the $\mathrm{OH}$ group at the ortho-position in the phenolic ring. However, the effect on the energy of the band $\mathrm{C}$ is very small. The substitution of $-\mathrm{OH}$ in the meta-position (derivative 2 ) seems to change the energy of the band B less than its substitution in ortho-position. When the disubstitution of $\mathrm{OH}$ in both meta and para position is done (derivative $\mathbf{3}$ ), the energies of both the bands $\mathrm{B}$ and $\mathrm{C}$ are decreased shifting them towards longer wavelengths by $\sim 50 \mathrm{~m} \mu$. The substitution of a $\mathrm{CH}_{3}$ group for $\mathrm{H}$ of $\mathrm{OH}$ in meta position of the phenolic ring (derivative 4) further decreases the energy of both the bands. The effect of solvents on both the bands are very small.

In the light of the above discussion the bands B and $\mathrm{C}$ may be assigned to the transitions similar to ${ }^{1} \mathrm{~B} \leftarrow{ }^{1} \mathrm{~A}$ and ${ }^{1} \mathrm{G} \leftarrow{ }^{1} \mathrm{~A}$ of stilbene. The d-orbitals of iodide ion loosely bonded to nitrogen atom are also involved in the transitions giving rise to the band C.

In the case of alkaline aqueous solution the $\mathrm{H}$ of the $\mathrm{OH}$ groups present in the phenolic ring is removed forming corresponding anhydro-salts, also known as betains. The band $\mathrm{A}$ in alkaline aqueous solution may be assigned to the betains. The appearance of the band A in DMF also suggests the formation of betain in DMF. The effect of solvent on band A exhibits a blue shift in changing the band from DMF to alkaline water. This blue shift is characteristic of the $n \rightarrow \pi^{*}$ transitions. This transition removes an electron from the pair of nonbonding orbitals on oxygen to the $\pi^{*}$-orbitals. Hence this band may be assigned to $\mathrm{n}_{0} \rightarrow \pi^{*}$ transitions, where $n$ orbitals are localized predominently on the oxygen atom of the betains.

\section{Experimental}

The absorption measurements were carried out with Carl Zeiss Jena VSU-2 spectrophotometer in the region $200-1100 \mathrm{~m} \mu$ at $25^{\circ} \pm 0.1^{\circ} \mathrm{C}$. The compounds used for the preparation of the derivatives and the solvent were of highest purity available (A.R. or spectrograde). The $1 \mathrm{M} \mathrm{NaOH}$ solution in water was used as alkaline aqueous solution.

The authors are thankful to Dr. J. P. SAxena, Reader, Chemical Laboratories, University of Jodhpur, for helpful discussion and S. P. T. is also thankful to U.G.C., India, for supporting the work. 